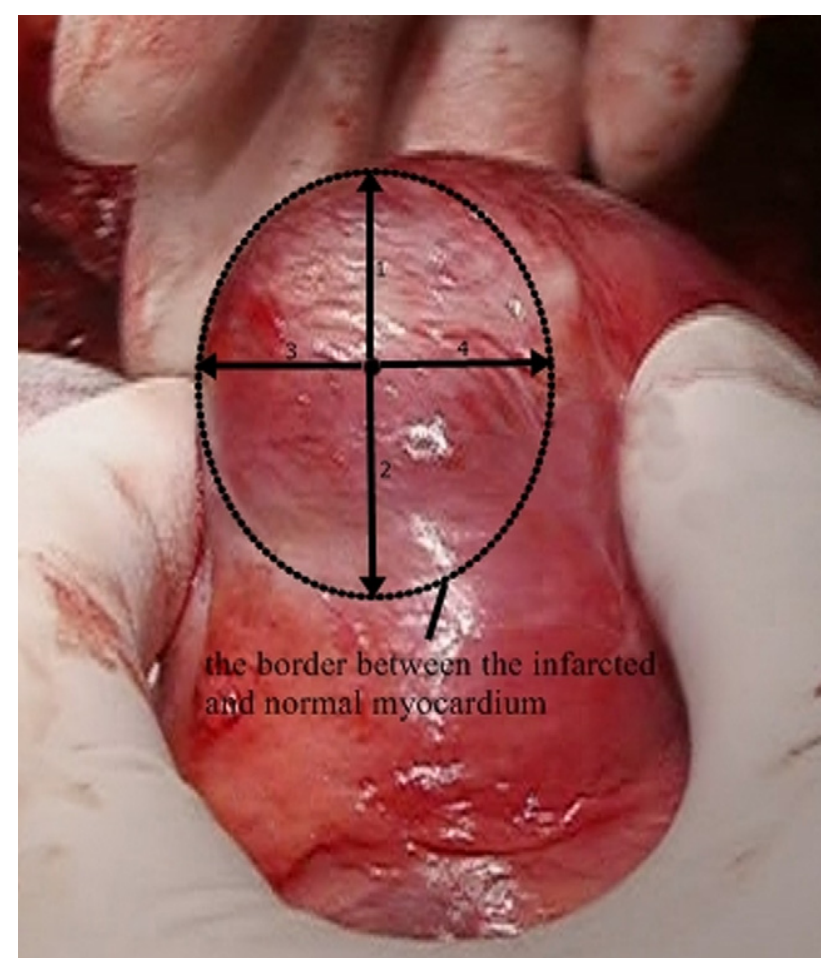

FIGURE 1. Bipolar radiofrequency ablation was performed as a cross shape by clamping the full thickness of the ventricle wall. Two longitudinal lines $(1,2)$ were made parallel to the interventricular groove. The short-axis lines $(3,4)$ were made perpendicular to the longitudinal lines. All the lines extended to the border between the infarcted and normal myocardium.

remain in nontransmural tissue. The bipolar system measures the tissue impedance and adjusts its power output accordingly. Once the impedance reaches a defined threshold, the system automatically terminates the power output, minimizing tissue damage from overablation, and thus protecting the myocardium. ${ }^{5}$ The procedure effectively disrupts reentrant cycles of the ventricular aneurysm, reducing or eliminating VA recurrence.

\section{CONCLUSIONS}

In the case presented, we performed bipolar radiofrequency ablation in addition to LVA placation during OPCAB. Consequently, we not only corrected the structural and functional abnormalities associated with the aneurysm but also provided electrophysiologic treatment and decreased the risk associated with cardiopulmonary bypass, which is particularly important in patients with ventricular aneurysm and poor cardiac function. It is a valuable technique with broad clinical applications, although the medium- and long-term efficacy of this method remain to be determined.

\section{References}

1. Matthias Bechtel JF, Tolg R, Graf B, Richardt G, Noetzold A, Kraatz EG, et al. High incidence of sudden death late after anterior LV-aneurysm repair. Eur J Cardiothorac Surg. 2004;25:807-11.

2. Samore NA, Imran Majeed SM, Kayani AM, Bhalli MA, Shabbir M. Outcome of radiofrequency catheter ablation as a non-pharmacological therapy for idiopathic ventricular tachycardia. J Coll Physicians Surg Pak. 2009;19:548-52.

3. Yu Y, Gu CX, Wei H, Liu R, Chen CC, Fang Y. Repair of left ventricular aneurysm during off-pump coronary artery bypass surgery. Chin Med. 2005;118:1072-5.

4. Tada H, Kurita T, Ohe T, Shimizu W, Suyama K, Aihara N, et al. Clinical and electrophysiologic features of idiopathic left ventricular aneurysm with sustained ventricular tachycardia. Int J Cardiol. 1998;67:27-38.

5. Voeller RK, Zierer A, Lall SC, Sakamoto S, Schuessler RB, Damiano RJ Jr. Efficacy of a novel bipolar radiofrequency ablation device on the beating heart for atrial fibrillation ablation: a long-term porcine study. J Thorac Cardiovasc Surg. 2010;6:203-8

\title{
Percutaneous embolization of patent intercostal artery causing persistent type II endoleak and sac enlargement of thoracoabdominal aneurysm 2 years after hybrid repair
}

Firas F. Mussa, MD, MS, FACS, Thomas S. Maldonado, MD, FACS, and Charles F. Schwartz, MD, FACS, New York, NY

From the Cardiac and Vascular Institute and Aortic Disease Center, New York University School of Medicine, New York, NY.

Disclosures: Authors have nothing to disclose with regard to commercial support. Received for publication April 22, 2012; revisions received May 27, 2012; accepted for publication June 18, 2012; available ahead of print July 23, 2012

Address for reprints: Firas F. Mussa, MD, MS, FACS, Division of Vascular and Endovascular Surgery, Aortic Disease Center, New York University School of Medicine, 530 First Ave, Suite 6F, New York, NY 10016 (E-mail: firas.mussa@ nyumc.org). J Thorac Cardiovasc Surg 2012;144:e102-6

$0022-5223 / \$ 36.00$

Copyright (C) 2012 by The American Association for Thoracic Surgery http://dx.doi.org/10.1016/j.jtcvs.2012.06.056
Hybrid repair of thoracoabdominal aortic aneurysms has been shown to be safe and effective in properly selected patients. ${ }^{1}$ The operation is a major undertaking, however, and the risks of major complications is real. Among the less reported complications is type II endoleak after such repair. This report underscores the management of a type II endoleak from an intercostal artery causing sac enlargement that was treated by direct percutaneous puncture of the endoleak nidus and coil embolization of the feeding artery. 


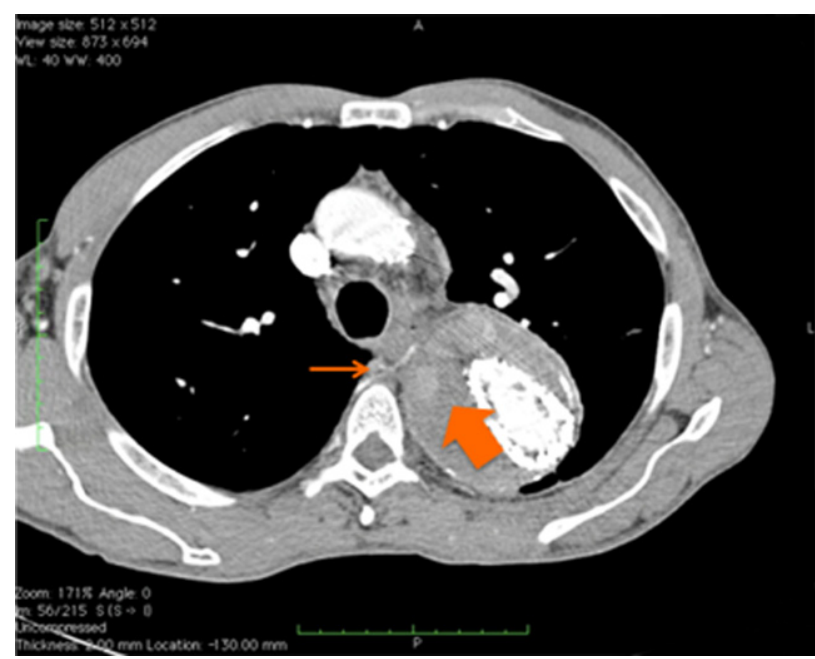

FIGURE 1. Computed tomographic angiography. Type II endoleak (thick arrow) from feeding intercostal artery (thin arrow).

Institutional review board approval was obtained to report this case.

\section{CLINICAL SUMMARY}

A 57-year-old man with a history of hypertension, hypercholesterolemia, and open repair of abdominal aortic aneurysm 10 years previously with bifurcated graft was seen for elective repair of a $6.7-\mathrm{cm}$ thoracoabdominal aneurysm. After informed consent had been obtained, the patient underwent staged hybrid repair in June 2010 with total abdominal debranching of the celiac artery, superior mesenteric artery, and bilateral renal arteries. The origins of all visceral and renal arteries were ligated. The next day, the patient underwent endovascular exclusion of the aneurysm with 4 TAG devices (W.L. Gore \& Associates, Flagstaff, Ariz). The proximal landing zone was at the left carotid artery, and the distal landing zone was in the existing Dacron polyester fabric graft from the previous abdominal aortic aneurysm repair. The left subclavian artery was maintained in the circulation with a chimney $10 \times 40$ Absolute Pro self-expanding stent (Abbott Vascular, Santa Clara, Calif). The patient was followed up according to protocol, and the aneurysm had shrunk in size to $5.7 \mathrm{~cm}$ at 12 months. At 18 months, the patient was noted to have new type II endoleak with sac enlargement to $6.3 \mathrm{~cm}$. There was no contrast enhancement on either seal zone, ruling out type I endoleak. The endoleak was at the superior third of the stent-graft at the level of the fifth intercostal space, with visible intercostal artery at same level (Figure 1). Because of the increase in aneurysmal size, we decided to intervene with the endoleak. The patient was free of symptoms, and his laboratory values
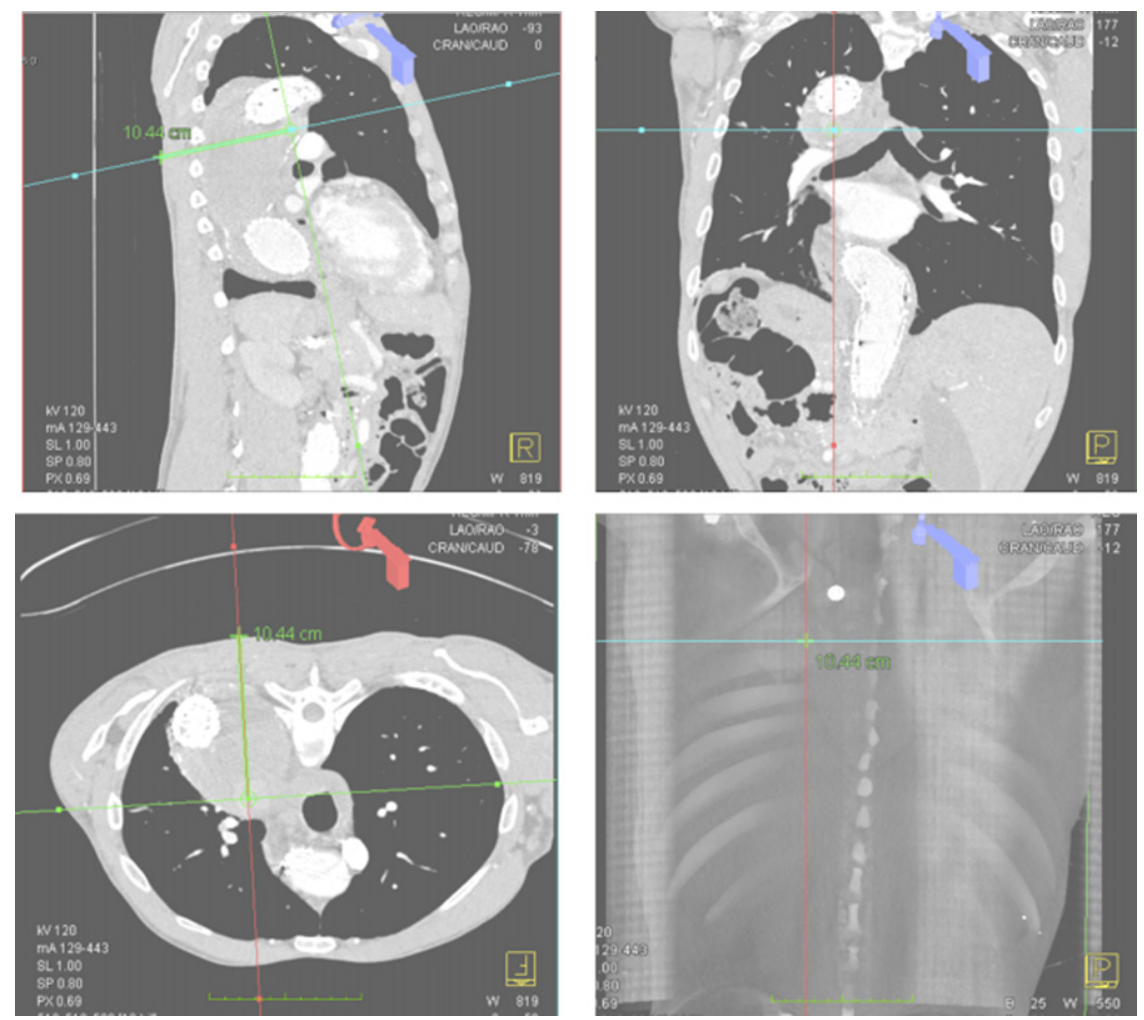

FIGURE 2. The iGuide image showing trajectory of needle from skin to the endoleak nidus. The nidus is located along the inner aortic curve and away from the proximal landing zone. 


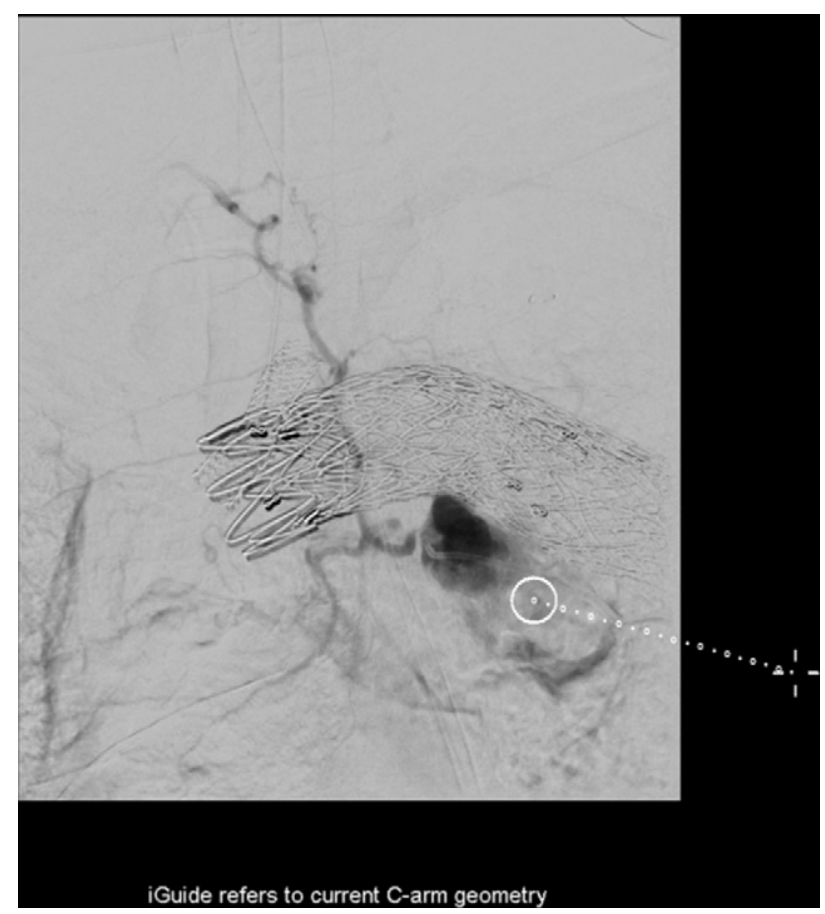

FIGURE 3. Contrast injection into the endoleak nidus demonstrating the 2 intercostal arteries filling into the aneurysm through a common trunk.

revealed a hemoglobin level of $8.2 \mathrm{~g} / \mathrm{dL}$ and a creatinine level of $1.3 \mathrm{mg} / \mathrm{dL}$.

In the operating room and with the patient in the prone position, a dry $360^{\circ}$ rotational computed tomographic (CT) scan was performed with DynaCT (Axiom Artis; Siemens, Erlangen, Germany). This was fused with the preoperative contrast-enhanced CT angiography to use during live fluoroscopy. A stab incision was made on the skin, and a long spinal needle was used to access the endoleak. The iGuide software (Siemens, Erlangen, Germany) was used to map the trajectory between skin and endoleak nidus (Figure 2). The needle followed the iGuide trajectory, as determined by the fused image between the CT scan and fluoroscopy. Once inside the nidus, the position of the needle was confirmed angiographically. A long $6 \mathrm{~F}$ sheath was then inserted over a stiff wire, and angiography demonstrated a type II endoleak with 2 intercostal arteries with a common trunk that was filling into the aneurysm (Figure 3). A guidewire and angled glide catheter (Terumo, Somerset, NJ) were used to access the feeding intercostal arteries and embolize the common trunk with platinum coils (0.018-inch diameter micro Nestor coils; Cook Medical Inc, Bloomington, Ind; Figure 4). The endoleak nidus and outflow tract were embolized with $3 \mathrm{~mL}$ of n-butyl cyanoacrylate glue (Trufill; Cordis Corporation, Miami Lakes, Fla; Figure 5). Ethiodol (Savage Laboratories, Melville, NY) and n-butyl cyanoacrylate were mixed at a 3:1 ratio, and tantalum was added to make the mixture radiopaque.

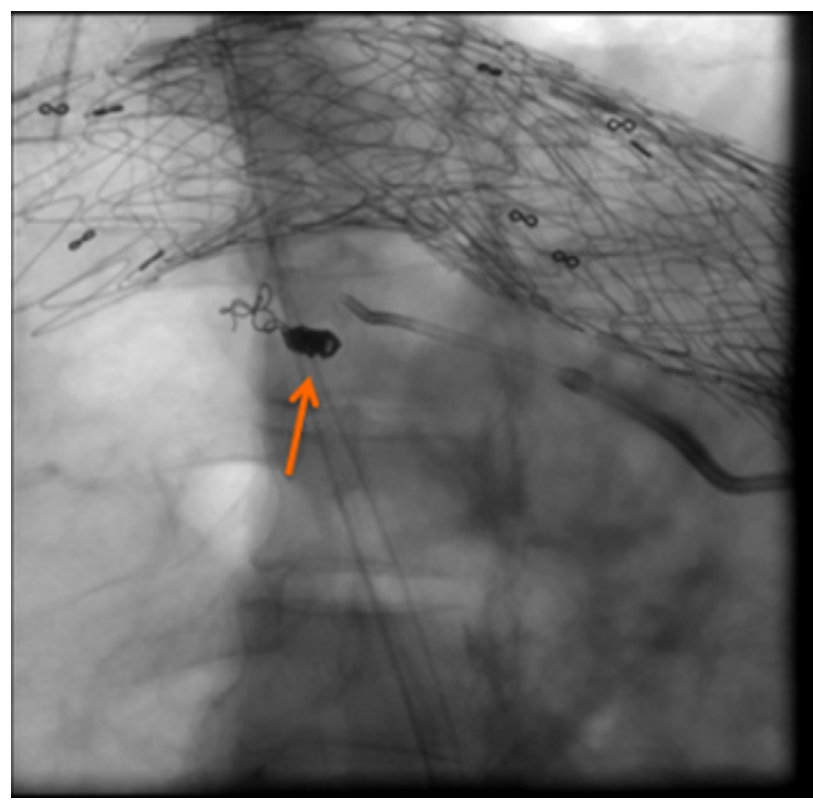

FIGURE 4. Coils deployed in common trunk of the intercostal artery (arrow).

Postoperative chest radiograph was normal in appearance. The patient was discharged home on postoperative day 1, after noncontrast CT showed stable aneurysm size. A follow-up CT angiogram was completed 30 days later and showed no evidence of endoleak (Figures 6 and 7).

\section{DISCUSSION}

To increase the feasibility of endovascular repairs of thoracoabdominal aneurysms, adjunctive open

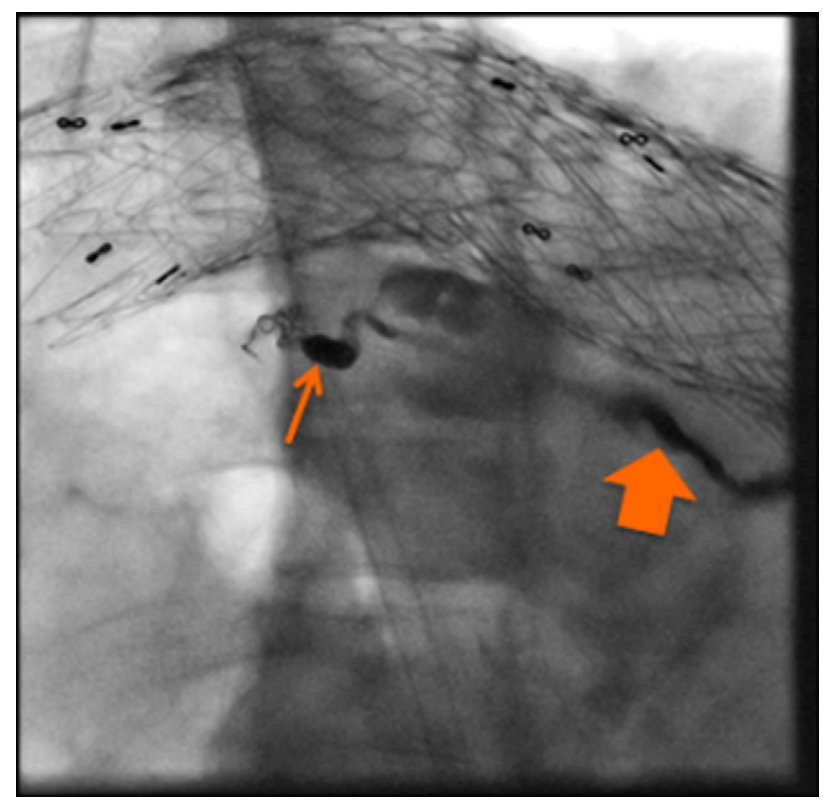

FIGURE 5. There is $3 \mathrm{~mL}$ of n-butyl cyanoacrylate glue injected in the endoleak nidus (thick arrow). Thin arrow indicates the coils in the common trunk. 


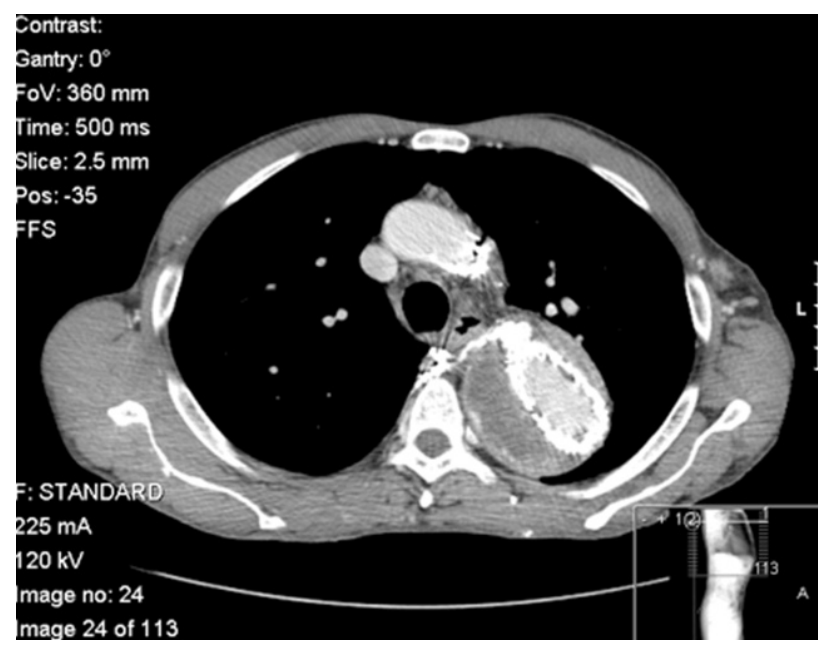

FIGURE 6. Follow-up computed tomographic scan at 1 month. Successful embolization, with no evidence of type II endoleak and stable-size aneurysm sac.

surgical bypasses may be required to provide adequate landing zones. ${ }^{2,3}$ The hybrid approach of combining endovascular repairs with open surgical techniques in properly selected cases provides a valuable alternative, particularly for patients who are at high risk with open repairs or have unsuitable anatomies for endovascular approaches alone. ${ }^{1}$

The incidence of endoleak after thoracic endovascular aortic repair (TEVAR) is $5 \%$ to $20 \%$, similar to endovascular abdominal aortic aneurysm repair (EVAR). ${ }^{4}$ The diagnosis and management of endoleaks after EVAR have been well described, ${ }^{5}$ but less is known about the significance and implications of endoleaks after TEVAR. ${ }^{6,7}$ Expectant management of type II endoleak after thoracic aneurysm repair is usually recommended, because these endoleaks rarely lead to sac enlargement and may undergo spontaneous thrombosis during follow-up. ${ }^{4}$ Should they require treatment, transarterial embolization of endoleak is more challenging after TEVAR than after EVAR, and a transthoracic approach may require violating the pleural cavity. ${ }^{8}$ In addition, embolization of intercostal arteries carries the risk of spinal infarction and neurologic deficit. ${ }^{9}$ Despite the length of coverage and previous aortic surgery, we elected to defer the placement of spinal drain to the postoperative period in case neurologic deficit developed. Stavropoulos and colleagues ${ }^{10}$ described a case similar to ours. They reported on type II endoleak after TEVAR for ruptured thoracic aneurysm that was treated by percutaneous sac puncture through the lung parenchyma. Our case was different in that it was a delayed endoleak (18 months) in a thoracoabdominal aneurysm. In addition, we selectively embolized the feeding intercostal artery in addition to the endoleak nidus. Heye and associates ${ }^{11}$ reported on a patient with type II endoleak 2 weeks after a hybrid

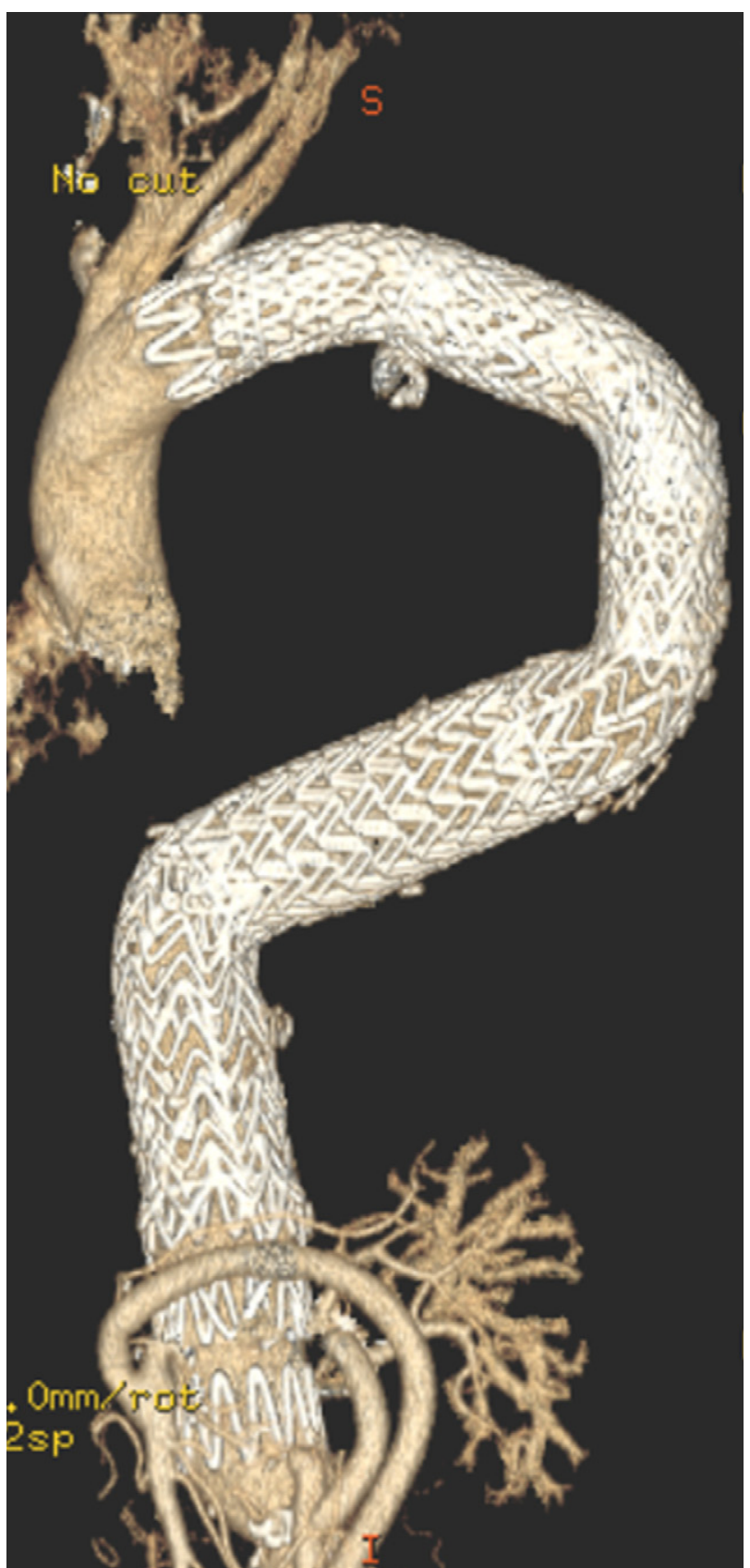

FIGURE 7. Three-dimensional computed tomographic angiography at 1 month.

thoracoabdominal aortic aneurysm repair. The endoleak was originating from a celiac artery that had not been ligated at its origin. The endoleak was successfully treated by transcatheter coil embolization. ${ }^{11}$

In our case, we confirmed the absence of type I or III endoleaks by performing digital subtraction angiography a few days before direct sac puncture. We used the combination of fluoroscopic and DynaCT guidance to treat the type II endoleak, which was located in the proximal third 
of the sac along the inner curve of the aortic arch. DynaCT acquired non-contrast-enhanced images by rotating the digital detector of the $\mathrm{C}$-arm $360^{\circ}$ around the point of interest. The acquired images were then fused with the preoperative CT angiography to be used during live fluoroscopy. The built-in iGuide software allowed real-time access to the endoleak nidus and feeding vessels during embolization. The trajectory of the spinal needle between skin and the endoleak was accurately mapped. The needle was advanced under fluoroscopic guidance while changing the angle of the image intensifier at $90^{\circ}$ multiple times to confirm accurate positioning and prevent inadvertent graft puncture. Once inside the endoleak, direct injection of the sac was needed to confirm the absence of proximal type I endoleak.

We performed the embolization with 2 agents, glue and coils, for 2 reasons. First, the use of coils to occlude the main feeding vessel avoids accidental migration of glue to nontarget end vessels. Second, the use of glue to cast the aneurysm isolates the sac from systemic pressure and increase the success of endoleak treatment by reducing the rate of late recanalization. ${ }^{12}$

Occasionally, high radiopacity and streak artifacts of glue may interfere with detection of persistent endoleaks on follow-up CT scan. Comparison between noncontrast and contrast images can help to detect endoleak recurrence. In addition to unchanged or shrinking aneurysmal size, replacement of the embolic material at the endoleak nidus and outflow vessels can be regarded as a successful embolization.

In conclusion, this is a report of direct puncture of the aneurysmal sac for type II endoleak caused by persistent intercostal artery after hybrid repair of thoracoabdominal aneurysm. It underscores the indispensable role of the combination of fluoroscopy, DynaCT, and iGuide to make this approach safe and effective.

\section{References}

1. Zhou W, Reardon M, Peden EK, Lin PH, Lumsden AB. Hybrid approach to complex thoracic aortic aneurysms in high-risk patients: surgical challenges and clinical outcomes. J Vasc Surg. 2006;44:688-93.

2. Quinones-Baldrich W, Jimenez JC, DeRubertis B, Moore WS. Combined endovascular and surgical approach (CESA) to thoracoabdominal aortic pathology: a 10-year experience. J Vasc Surg. 2009;49:1125-34.

3. Donas KP, Czerny M, Guber I, Teufelsbauer H, Nanobachvili J. Hybrid openendovascular repair for thoracoabdominal aortic aneurysms: current status and level of evidence. Eur J Vasc Endovasc Surg. 2007;34:528-33.

4. Alsac JM, Khantalin I, Julia P, Achouh P, Farahmand P, Capdevila C, et al. The significance of endoleaks in thoracic endovascular aneurysm repair. Ann Vasc Surg. 2011;25:345-51

5. Baum RA, Stavropoulos SW, Fairman RM, Carpenter JP. Endoleaks after endovascular repair of abdominal aortic aneurysms. J Vasc Interv Radiol. 2003;14:1111-7.

6. Grabenwoger M, Fleck T, Ehrlich M, Czerny M, Hutschala D, Schoder M, et al. Secondary surgical interventions after endovascular stent-grafting of the thoracic aorta. Eur J Cardiothorac Surg. 2004;26:608-13.

7. Parmer SS, Carpenter JP, Stavropoulos SW, Fairman RM, Pochettino A, Woo EY, et al. Endoleaks after endovascular repair of thoracic aortic aneurysms. $J$ Vasc Surg. 2006;44:447-52

8. Baum RA, Carpenter JC, Golden MA, Velazquez OC, Clark TW, Stavropoulos SW, et al. Treatment of type 2 endoleaks after endovascular repair of abdominal aortic aneurysms: comparison of transarterial and translumbar techniques. J Vasc Surg. 2002;35:23-9. Erratum in: J Vasc Surg. 2002;35:852.

9. Kim JH, Yeon JE, Jong YK, Seo WK, Cha IH, Seo TS, et al. Spinal cord injury subsequent to transcatheter arterial chemoembolization in patients with hepatocellular carcinoma. Dig Liver Dis. 2010;42:67-70.

10. Stavropoulos SW, Park J, Fairman R, Carpenter J. Type 2 endoleak embolization comparison: translumbar embolization versus modified transarterial embolization. J Vasc Interv Radiol. 2009;20:1299-302.

11. Heye SJ, Vaninbroukx J, Daenens K, Maleux G. Transcatheter embolization of a type II endoleak after hybrid repair for thoracoabdominal aortic aneurysm. $J$ Vasc Interv Radiol. 2011;22:379-84.

12. Stavropoulos SW, Kim H, Clark TW, Fairman RM, Velazquez O, Carpenter JP. Embolization of type 2 endoleaks after endovascular repair of abdominal aortic aneurysms with use of cyanoacrylate with or without coils. J Vasc Interv Radiol. 2005;16:857-61.

\title{
Surgical management after stent-graft failure during the frozen elephant trunk technique for acute type A aortic dissection
}

\author{
Maximilian Luehr, MD, ${ }^{\mathrm{a}}$ Christian D. Etz, MD, PhD, ${ }^{\mathrm{a}, \mathrm{b}}$ Friedrich-Wilhelm Mohr, MD, PhD, ${ }^{\mathrm{a}}$ and \\ Michael A. Borger, MD, PhD, ${ }^{\mathrm{a}}$ Leipzig, Germany, and New York, NY
}

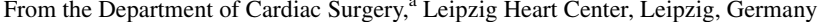
and the Department of Cardiothoracic Surgery, ${ }^{b}$ Mount Sinai School of Medicine, New York, NY

Disclosures: Authors have nothing to disclose with regard to commercial support.

Presented at The American Association for Thoracic Surgery Aortic Symposium, New York, New York, April 26-27, 2012.

Received for publication June 10, 2012; accepted for publication July 9, 2012; available ahead of print July 30, 2012

Address for reprints: Maximilian Luehr, MD, Department of Cardiac Surgery, Leipzig Heart Center, Struempellstrasse 39, 04289 Leipzig, Germany (E-mail: maximilian.luehr@med.uni-leipzig.de).

J Thorac Cardiovasc Surg 2012;144:e106-8

$0022-5223 / \$ 36.00$

Copyright (c) 2012 by The American Association for Thoracic Surgery

http://dx.doi.org/10.1016/j.jtcvs.2012.07.006
}

A 37-year-old woman was admitted to our institution on an emergency basis owing to acute type A aortic dissection with involvement of the entire thoracoabdominal aorta extending into the iliac arteries.

After cannulation of the right axillary artery, a median sternotomy was performed and cardiopulmonary bypass was subsequently initiated. The patient was cooled to a body core temperature of $25^{\circ} \mathrm{C}$ (bladder). The brachiocephalic trunk was clamped, the aortic arch was opened, and the left carotid artery was cannulated to allow for bilateral selective cerebral perfusion $\left(800 \mathrm{~mL} / \mathrm{min}\right.$ at $\left.18^{\circ} \mathrm{C}\right)$. The 